\title{
A phase II, multicentre trial evaluating the efficacy of de-escalated bisphosphonate therapy in metastatic breast cancer patients at low-risk of skeletal-related events
}

\author{
Christina L. Addison • Nathaniel Bouganim • John Hilton • Lisa Vandermeer • \\ Susan Dent • Eitan Amir • Sean Hopkins • Iryna Kuchuk • Roanne Segal • \\ Xinni Song · Stan Gertler · Sasha Mazzarello • George Dranitsaris • \\ Daylily Ooi • Gregory Pond • Mark Clemons
}

Received: 31 January 2014/ Accepted: 3 March 2014/Published online: 18 March 2014

(C) The Author(s) 2014. This article is published with open access at Springerlink.com

\begin{abstract}
The optimal frequency of intravenous (IV) bisphosphonate administration is unclear. We thus performed a study evaluating the effects of switching from 3-4 to 12 weekly therapy in patients with biochemically defined low-risk bone metastases. Patients with serum C-telopeptide (CTx) levels $\leq 600 \mathrm{ng} / \mathrm{L}$ after $\geq 3$ months of 3-4 weekly IV pamidronate were switched to 12 weekly therapy for 48 weeks. Primary endpoint was the proportion of patients maintaining CTx levels in the lower-risk range. All endpoints (serum CTx and bone-specific alkaline phosphatase (BSAP), skeletal-related events (SREs) and self-reported pain) were measured at baseline, 6, 12, 24, 36 and 48 weeks. Treatment failure was defined as biochemical failure (CTx $>600 \mathrm{ng} / \mathrm{L})$ or a SRE. Exploratory biomarkers including; serum TGF- $\beta$, activin-A, bone sialoprotein (BSP), procollagen type $1 \mathrm{~N}$-terminal propeptide and urinary N-telopeptide (NTx) were assessed at baseline as predictors for failure to complete treatment.
\end{abstract}

Christina L. Addison and Nathaniel Bouganim contributed equally to this project.

C. L. Addison - N. Bouganim · J. Hilton - L. Vandermeer ·

S. Dent $\cdot$ S. Hopkins $\cdot$ I. Kuchuk · R. Segal $\cdot$ X. Song ·

S. Gertler · S. Mazzarello · G. Dranitsaris · M. Clemons (凹)

Division of Medical Oncology, Ottawa Hospital Cancer Centre,

501 Smyth Road, Box 912, Ottawa, ON K1H 8L6, Canada

e-mail: mclemons@toh.on.ca

C. L. Addison - N. Bouganim - J. Hilton - L. Vandermeer ·

S. Dent - S. Hopkins · I. Kuchuk - R. Segal · X. Song ·

S. Gertler · S. Mazzarello · G. Dranitsaris · M. Clemons

Department of Medicine, University of Ottawa, Ottawa, Canada

C. L. Addison - M. Clemons

Centre for Cancer Therapeutics, Ottawa Hospital Research

Institute, Ottawa, Canada
Seventy-one patients accrued and 43 (61\%) completed 48 weeks of de-escalated therapy. Reasons for failure to complete treatment included; biochemical failure $(\mathrm{CTx}>600 \mathrm{ng} / \mathrm{L}) \quad(n=10, \quad 14.1 \%), \quad$ on-study $\quad \mathrm{SRE}$ $(n=9,12.7 \%)$, disease progression $(n=7,9.9 \%$ including death from disease $[n=1,1.4 \%])$ or patient choice $(n=2,2.8 \%)$. Elevated baseline levels of CTx, BSAP, NTx and BSP were associated with treatment failure. The majority of patients in this biochemically defined low-risk population could switch from 3-4 weekly to 12 weekly bisphosphonate therapy with no effect on CTx levels or SREs during the 48 week study. Larger trials are required to assess the roles of biomarkers as predictors of adequacy of de-escalated therapy.

Keywords Bisphosphonate - Breast cancer $\cdot$ Bone metastasis - Skeletal related event - Biomarker . De-escalated 


\section{Background}

Bisphosphonates are administered every 3-4 weeks to patients with bone metastases from breast cancer, based on experience in treating hypercalcaemia of malignancy [1] as well as for convenience (coinciding with the timing of most chemotherapy regimens). However, this rationale ignores both the pharmacodynamics of bone-targeted agents which have activity in bone for many years [2] and the modest absolute magnitude of benefit from these therapies [3]. In addition, once started bone-targeted agents are rarely discontinued [4-6] and are usually given for longer than the 1-2 years evaluated in clinical trials [7-9]. As patients with metastases limited to the skeleton may have a prolonged disease course $[5,7,10,11]$, they will receive multiple doses of bisphosphonate [12]. This is important as adverse events such as renal toxicity [13], osteonecrosis of the jaw (ONJ) and atypical fractures [14-16], are associated with both the potency and the cumulative administered dose [17]. Frequent therapy also has financial and quality of life implications for patients and health care providers [18].

A number of completed or ongoing trials [19-25] have evaluated the safety and efficacy of reduced dosing intervals of bisphosphonates. However, use of skeletal related events (SREs), defined as pathological fractures, radiotherapy/surgery to bone, spinal cord compression or hypercalcaemia as the primary study endpoint [19], requires a large sample size and extended follow up. Consequently, smaller studies have utilised biomarkers of bone resorption, such as, N- and C-telopeptides (NTx and CTx respectively) as surrogate markers of SRE risk [26-28].

In a small pilot randomised study comparing 3-4 weekly with 12 weekly pamidronate in patients with biochemically defined low-risk disease, we successfully demonstrated similar control of serum CTx between the two study arms with $72 \%$ of patients maintaining control of CTx in the deescalated arm [20]. Here, we report on a larger cohort of de-escalated (every 12 weeks) bisphosphonate therapy in patients with biochemically defined low-risk bone disease. It was hypothesized that de-escalated therapy will provide similar control of bone resorption for a period of 1 year in these lower risk patients. In addition, through the prospective collection of serum and urine samples, we evaluated if alternative biomarkers correlated with patient outcomes.

\section{Materials and methods}

Study population

Women with breast cancer and radiologic, scintigraphic, and/or biopsy confirmed bone metastases who had received at least 3 months of 3-4 weekly IV pamidronate were enrolled. Eligible women needed to have evidence of lower-risk metastatic bone disease defined as baseline serum CTx $<600 \mathrm{ng} / \mathrm{L}$. This threshold was selected based on data from large prospective datasets [26], demonstrating that it is indicative of the range between low and medium risk disease. Patients were to have had no change in systemic anti-cancer therapy or radiation therapy in the 28 days prior to signing consent [21]. The study was approved by the Ontario Cancer Research Ethics Board, Toronto, Canada. As part of the main study consent, patients could also optionally consent to the collection of urine and serum samples for future research.

\section{Trial design}

All study participants were switched from 3-4-weekly to 12 weekly pamidronate. Baseline levels of fasting serum CTx and bone-specific alkaline phosphatase (BSAP), parathyroid hormone (PTH) and 25-hydroxyvitamin D were measured. Serum CTx and BSAP were reassessed at weeks 6, 12, 24, 36 and 48. Data on self-reported pain using the Brief Pain Inventory (BPI) [29], the Functional Assessment of Cancer Therapy-Bone Pain (FACT-BP) [30], and the occurrence of SREs and analgesic use were also collected at these time points. All patients were advised to take calcium (1,200-1,500 mg/day) and vitamin $\mathrm{D}_{3}$ (800-1,000 IU/day) while on study.

\section{Endpoints}

The primary endpoint was the proportion of patients maintaining CTx levels within the low risk range ( $\leq 600 \mathrm{ng} / \mathrm{L}$ ) at 48 weeks. However, the primary endpoint was changed to the proportion of patients coming off study for any reason at 48 weeks. This was due to evidence that patients were being removed from treatment before 48 weeks due to SRE and withdrawals. The revised primary endpoint is therefore the most conservative result. Secondary endpoints included: frequency of SREs, change in serum BSAP and change in self-reported pain. Treatment failure was defined as either loss of biochemical control (defined as confirmed CTx levels $>600 \mathrm{ng} / \mathrm{L}$ ) or an on-study SRE. Due to CTx variability, if a patient had an elevation $>600 \mathrm{ng} / \mathrm{L}$ at the predefined study time points, then a repeat measure was taken 4 weeks later. If CTx remained elevated, then that patient was considered a treatment failure. Some patients did not complete the study due to withdrawal, progressive disease, or death.

Exploratory analyses assessing the utility of putative biomarkers of bone turnover or tumour progression as predictors of treatment failure were also conducted. Biomarkers of interest with previous evidence of a role in bone 
metastases included: serum-transforming growth factor (TGF)- $\beta 1[31,32]$, activin A [33-36], procollagen type $1 \mathrm{~N}$-terminal propeptide (P1NP) [37-39], bone sialoprotein (BSP) [40] and urinary NTx levels [41, 42].

\section{Biochemical analysis}

Blood was drawn in the morning following an overnight fast and prior to pamidronate infusion. Samples were allowed to clot and were centrifuged at $4{ }^{\circ} \mathrm{C}$ for $10 \mathrm{~min}$ at 3,400 RPM. Serum was frozen at $-80{ }^{\circ} \mathrm{C}$ until analysis. Urine was collected as a second pass, fasting specimen and frozen at $-80{ }^{\circ} \mathrm{C}$ until analysis. Serum CTx was measured by chemiluminescence immunoassay using CrossLaps ${ }^{\circledR}$ on an IDS iSYS automated analyzer. Analytical precision (coefficient of variation, CV) was $11.3 \%$ at $210 \mathrm{ng} / \mathrm{L}$ and $6.4 \%$ at $850 \mathrm{ug} / \mathrm{L}$. Serum BSAP was measured by a chemiluminescence assay, Ostase ${ }^{\circledR}$, on the Beckman Coulter Unicel DxI. The CV is $7.7 \%$ at $10.0 \mathrm{ug} / \mathrm{L}$ and $7.5 \%$ at $44.2 \mathrm{ug} / \mathrm{L}$. 25-hydroxyvitamin D and PTH were measured by a chemiluminescence assays, on the IDS iSYS or Beckman Coulter Unicel DxI, respectively.

Alternative biomarkers were measured using specific enzyme-linked immunosorbant assays (ELISA) in baseline serum samples for TGF- $\beta 1$ (Quantikine, R\&D Systems, Minneapolis $\mathrm{MN}$, detection limit $20 \mathrm{pg} / \mathrm{ml}$, interassay variability $\sim 8.3 \%$ ), activin A (Quantikine, R\&D Systems, Minneapolis $\mathrm{MN}$, detection limit $4 \mathrm{pg} / \mathrm{ml}$, interassay variability $\sim 5.9 \%$ ), P1NP (USCN Life Science Inc., Wuhan China, detection limit $15 \mathrm{pg} / \mathrm{ml}$, interassay variability $\sim 12 \%$ ), and BSP (USCN Life Science Inc., Wuhan China, detection limit $2 \mathrm{ng} / \mathrm{ml}$, interassay variability $\sim 12 \%$ ). Urine NTx levels were measured using the Osteomark assay (Alere, Scarborough ME, detection limit 2 $\mathrm{nM} \mathrm{BCE} / \mathrm{mM}$ creatinine, interassay variability $6.9 \%$ ). All samples were measured in duplicate and averaged values used. When values were below the threshold of detection for each respective assay, concentrations were assigned as 0.1 units below the sensitivity threshold for purposes of statistical analysis.

\section{Statistical analysis}

Sample size was determined by precision. Prior experience showed that $72 \%$ of patients treated with 12 weekly pamidronate maintained their telopeptides in the low risk range over a 48 week period [20]. Assuming this, 61 patients were needed to estimate this proportion with $95 \%$ confidence interval width of $20 \%$ (i.e. $\pm 10 \%$ ). After accounting for $10 \%$ drop-out, the required sample size was 68 patients. Patients who came off study for withdrawal, progressive disease or death were considered treatment failures for the primary analysis, but a supportive analysis was performed excluding these patients. For experimental biomarker analyses, exploratory statistical analysis was used to compare those eligible for biomarker analysis versus ineligible using Wilcoxon rank sum tests (continuous variables), Fisher's exact tests (binary variables) or the Cochran-Armitage test for trend (ordinal variables). Spearman correlation coefficients were calculated to explore for association between clinical factors and baseline biomarker levels. Logistic regression analyses were used to evaluate which factors were prognostic for completion of study therapy or having a SRE. Multivariable models were constructed using forward stepwise selection methods. All of the statistical analyses were performed using SAS software, and were two-sided with a $p$ value of 0.05 or less being considered statistically significant. No corrections were made for multiple significance testing.

\section{Results}

Patient enrolment and baseline characteristics

From October 2010 to September 2011, 84 patients were screened, with 71 eligible for enrolment (Fig. 1). Baseline patient characteristics are shown in Table 1. Patients had bone metastases for a median of 15 months (range 3-106) and received IV bisphosphonates for a median of 14 months (range 3-106). Of enrolled patients, 17 (24\%) had a SRE prior to study entry. Thirty-one patients (47\%) had metastases confined to the skeleton, 29 (41\%) patients had received one prior line of palliative systemic therapy while $20(28 \%)$ had received two lines of systemic therapy at the time of study entry.

\section{Baseline CTx and BSAP}

Median baseline CTx for all patients was $110 \mathrm{ng} / \mathrm{L}$ (range 25-850 ng/L, Table 1), and was similar for those patients eligible for exploratory analysis (Table $1, p=0.32$ ). Median baseline BSAP was $9.15 \mathrm{ug} / \mathrm{L}$ (range 4.9-1,190 ug/ $\mathrm{L}$, Table 1). There was a statistically significant difference in the median baseline BSAP levels for patients eligible for exploratory analysis versus those that were not, with patients not eligible for exploratory study having higher median BSAP levels (Table $1, p=0.007$ ).

\section{Pain scores}

Pain at study entry was assessed using two independent scoring methods, FACT-BP and BPI (assessed as BPIseverity and BPI-interference). In all cases, pain assessment scores were reflective of low to moderate pain, indicative of the low-risk patient population enrolled in this 


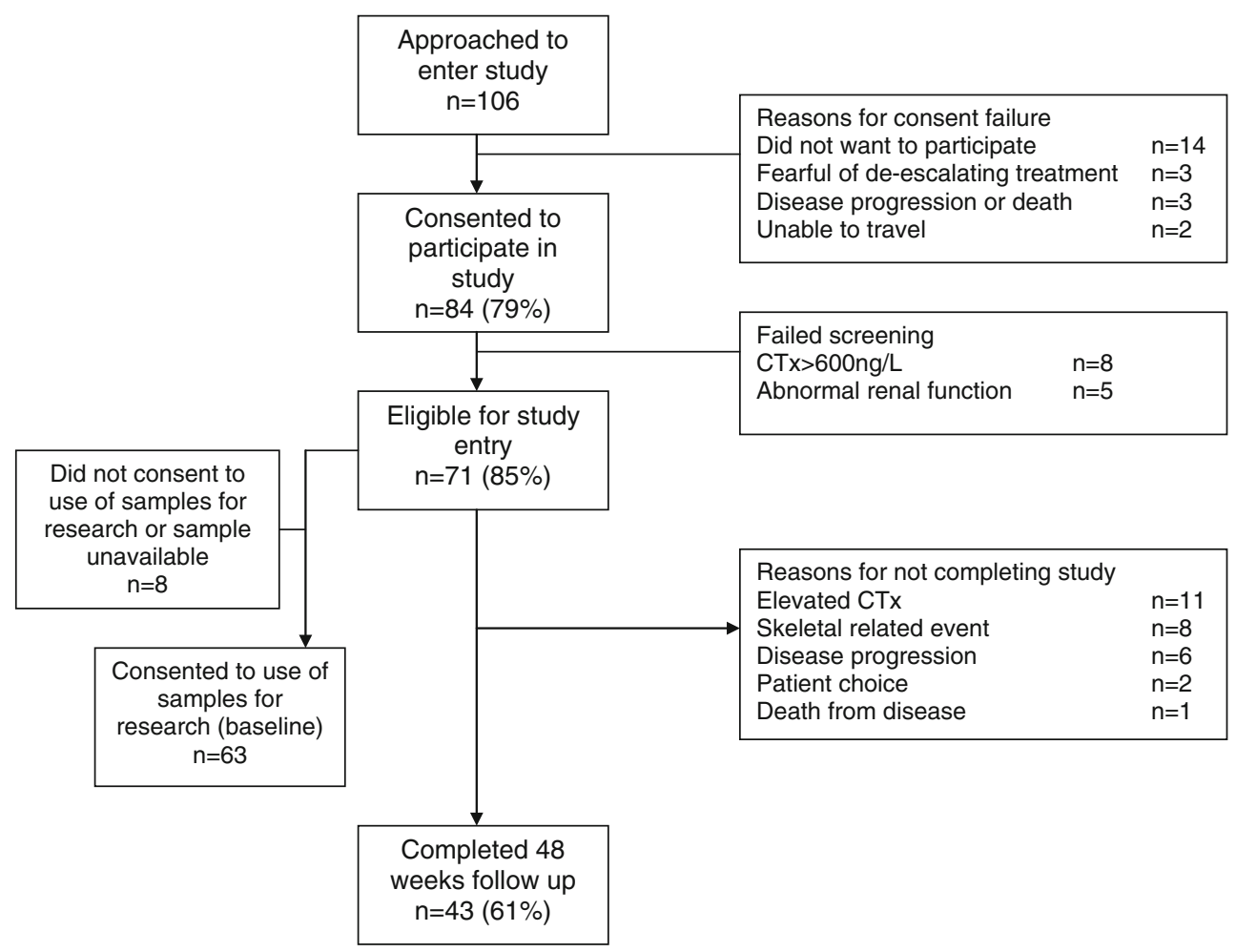

Fig. 1 CONSORT diagram

study (Table 1). In all cases, no significant difference was noted in baseline pain scores between those patients eligible for exploratory analysis and those that were not (Table 1).

Primary analysis

Of the 71 patients enrolled, $43(61 \%, 95 \%$ confidence interval [CI] 48-72\%) completed 48 weeks of de-escalated therapy. Twenty-eight patients did not complete 1 year of de-escalated therapy; 10 patients $(14.1 \%)$ came off study due to biochemical failure (CTx $>600 \mathrm{ng} / \mathrm{L}$ ), 9 $(12.7 \%)$ due to the development of a SRE, 6 patients $(8.5 \%)$ were withdrawn from study by their physician due to disease progression, and 1 patient $(1.4 \%)$ due to death from breast cancer. An additional 2 patients $(2.8 \%)$ did not complete one year of de-escalated therapy due to withdrawal of consent. We did not observe any bisphosphonate-specific toxicities such as renal impairment, ONJ or atrial fibrillation.

\section{Frequency of SREs}

As mentioned, $9(12.7 \%)$ patients who maintained CTx $<600 \mathrm{ng} / \mathrm{L}$ experienced on study SREs. In addition, of the 10 patients who came off study early due to elevated CTx, 4 of these patients subsequently developed a SRE. Thus, out of the 71 patients enrolled, a total of $13(17 \%)$ had a SRE within 1 year of study entry. In contrast, of the 8 screened patients who had signed consent but were ineligible for study entry due to baseline CTx $>600 \mathrm{ng} / \mathrm{L}, 6$ (75\%) had a SRE within the year even though they remained on 3-4 weekly bisphosphonate treatment. Of the 9 patients who withdrew from the study due to progression, death or patient's choice, 1 had a SRE within 1 year. This patient was taken off study by her oncologist due to disease progression, and her CTx was subsequently found to be $>600 \mathrm{ng} / \mathrm{L}$.

Exploratory analyses of additional putative biomarkers

Of the 71 enrolled patients, 63 (89\%) consented to use of bio-specimens for exploratory biomarker analyses (urine NTx, was available from 62 of these 63 patients). Median levels were: NTx $186 \mathrm{nM} \mathrm{BCE} / \mathrm{mM}$ creatinine (range 43-1,918); P1NP 34 pg/mL (range 3-125); BSP 44 ng/mL (range 2-290); TGF- $\beta 17 \mathrm{pg} / \mathrm{mL}$ (range 5-29); and activin A $399 \mathrm{pg} / \mathrm{mL}$ (range 187-5,904) (Table 1).

Association between biomarkers and clinical factors

Table 2 shows the Spearman correlation coefficient $(\rho)$ estimate measuring association between select clinical factors and baseline biomarkers. Baseline CTx and BSAP 
Table 1 Baseline characteristics

\begin{tabular}{|c|c|c|c|c|c|}
\hline & & All patients & $\begin{array}{l}\text { Eligible for } \\
\text { exploratory }\end{array}$ & $\begin{array}{l}\text { Not eligible for } \\
\text { exploratory }\end{array}$ & $p$ value \\
\hline$N$ & & 71 & 63 & 8 & \\
\hline $\begin{array}{l}\text { Duration of bone metastases } \\
(n=70), \text { months }\end{array}$ & Median (range) & $15(3,106)$ & $15(3,106)$ & $14(9,59)$ & 0.93 \\
\hline PTH & Median (range) & $6.5(1.6,65)$ & $6.2(1.6,65)$ & $7.7(3,13)$ & 0.67 \\
\hline Vitamin D & Median (range) & $93(5,203)$ & $93(5,203)$ & $90(49,138)$ & 0.49 \\
\hline $\begin{array}{l}\text { Months, taking Bisphosphonates } \\
\text { prior to starting study }\end{array}$ & Median (range) & $14(3,106)$ & $14(3,106)$ & $11(4,59)$ & 0.54 \\
\hline Baseline CTx & Median (range) & $110(25,850)$ & $110(25,740)$ & $235(25,850)$ & 0.32 \\
\hline Baseline BSAP $(n=70)$ & Median (range) & $9.15(4.9,1190.0)$ & $9.05(4.9,46.4)$ & $13.85(8.7,1190.0)$ & 0.007 \\
\hline FACT-BP subscale & Mean (sd) & $48.7(10.8)$ & $48.6(10.6)$ & $49.5(12.4)$ & 0.72 \\
\hline BPI-severity $(n=70)$ & Median (range) & $3(0,26)$ & $3(0,26)$ & $1(0,13)$ & 0.64 \\
\hline BPI-interference $(n=69)$ & Median (range) & $5(0,46)$ & $5(0,46)$ & $2.5(0,28)$ & 0.54 \\
\hline \multirow{7}{*}{$\begin{array}{l}\text { Total number of prior lines of } \\
\text { systemic therapy for metastatic } \\
\text { disease }\end{array}$} & 1 & $29(40.9)$ & $25(39.7)$ & $4(50.0)$ & \multirow[t]{7}{*}{$0.59^{\mathrm{b}}$} \\
\hline & 2 & $20(28.2)$ & $17(27.0)$ & $3(37.5)$ & \\
\hline & 3 & $10(14.1)$ & $10(15.9)$ & $0(0.0)$ & \\
\hline & 4 & $4(5.6)$ & $4(6.4)$ & $0(0.0)$ & \\
\hline & 5 & $3(4.2)$ & $3(4.8)$ & $0(0.0)$ & \\
\hline & 6 & $3(4.2)$ & $2(3.2)$ & $1(12.5)$ & \\
\hline & 7 & $2(2.8)$ & $2(3.2)$ & $0(0.0)$ & \\
\hline \multirow{5}{*}{$\begin{array}{l}\text { Total number of SRE prior } \\
\text { to study entry }\end{array}$} & 0 & $54(76.1)$ & $47(74.6)$ & $7(87.5)$ & \multirow[t]{5}{*}{$0.67^{\mathrm{a}}$} \\
\hline & 1 & $12(16.9)$ & $12(19.1)$ & $0(0.0)$ & \\
\hline & 2 & $3(4.2)$ & $2(3.2)$ & $1(12.5)$ & \\
\hline & 3 & $1(1.4)$ & $1(1.6)$ & $0(0.0)$ & \\
\hline & 4 & $1(1.4)$ & $1(1.6)$ & $0(0.0)$ & \\
\hline NTx $(n=63)$ & Median (range) & $186.1(43.3,1918.1)$ & $186.1(43.3,1918.1)$ & Not measured & - \\
\hline $\mathrm{P} 1 \mathrm{NP}(n=63)$ & Median (range) & $33940(3087,124933)$ & $33940(3087,124933)$ & Not measured & - \\
\hline $\operatorname{BSP}(n=63)$ & Median (range) & $43.8(1.99,290.4)$ & $43.8(1.99,290.4)$ & Not measured & - \\
\hline TGF- $\beta(n=63)$ & Median (range) & $16.6(5.1,29.4)$ & $16.6(5.1,29.4)$ & Not measured & - \\
\hline ActivinA $(n=63)$ & Median (range) & $398.6(187.4,5904.4)$ & $398.6(187.4,5904.4)$ & Not measured & - \\
\hline
\end{tabular}

${ }^{a}$ Fisher's exact test comparing $\geq 1$ versus 0

b Cochran-Armitage test for trend

had only weak to no association with any of the clinical factors measured. Of the exploratory baseline biomarkers measured, only baseline BSP and TGF- $\beta$ showed a moderate association with duration of bone metastases (Table 2, $\rho=0.36$ and $\rho=-0.40$, respectively), while no associations were noted between any of the other clinical factors of interest.

Prognostic factors for completion of 1 year of deescalated therapy

Baseline vitamin D, NTx, BSP and CTx were all statistically significant for completion of therapy (Table 3 ). Patients with higher serum 25-hydroxyvitamin D (OR 1.20, $95 \%$ CI 1.03-1.39), lower CTx (OR 0.96, $95 \%$ CI
0.93-0.99), lower NTx (OR 0.62, $95 \%$ CI 0.42-0.92) and lower BSP (OR 0.86, $95 \%$ CI 0.77-0.95) were all more likely to complete therapy. In multivariable analysis, vitamin D, NTx and BSP remained associated with likelihood of completion of therapy.

Prognostic factors for occurrence of on study SREs

Prognostic factors for on study SREs were also explored (Table 4). Baseline CTx or BSAP were not prognostic for having a SRE on-study ( $p=0.69$ and $p=0.80$, respectively). BPI-severity score was the only factor which was statistically significantly associated with likelihood of an on-study SRE (OR 1.15; $95 \%$ CI 1.03-1.28, $p=0.017$ ). 
Table 2 Association of clinical factors with baseline biomarker measurements

\begin{tabular}{lcccrrrrrrr}
\hline & Vitamin D & $\begin{array}{l}\text { Screening } \\
\text { CTx }\end{array}$ & $\begin{array}{l}\text { Baseline } \\
\text { CTx }\end{array}$ & BSAP & NTx & P1NP & BSP & TGF- $\beta$ & Activin A \\
\hline Weight & -0.11 & -0.06 & 0.15 & 0.09 & -0.00 & 0.20 & -0.17 & 0.28 & -0.07 \\
Height & -0.13 & -0.02 & -0.02 & -0.06 & -0.05 & -0.11 & 0.04 & -0.23 & 0.01 \\
BSA & -0.13 & -0.05 & 0.12 & 0.05 & -0.02 & 0.15 & -0.11 & 0.16 & -0.03 \\
Duration of bone mets & 0.17 & 0.10 & 0.04 & 0.13 & 0.00 & -0.07 & $\mathbf{0 . 3 6}$ & $-\mathbf{0 . 4 0}$ & 0.17 \\
PTH & -0.26 & 0.00 & -0.01 & -0.05 & 0.15 & -0.13 & -0.06 & -0.02 & -0.02 \\
FACT-BP subscale & 0.05 & -0.00 & -0.14 & 0.14 & -0.06 & -0.12 & -0.25 & 0.00 & -0.12 \\
BPI-severity & 0.09 & -0.22 & -0.06 & -0.22 & -0.13 & 0.19 & 0.03 & 0.12 & -0.02 \\
BPI-interference & 0.03 & -0.13 & 0.06 & -0.14 & 0.01 & 0.27 & 0.17 & 0.03 & -0.05 \\
Vitamin D & - & -0.06 & -0.19 & -0.05 & -0.11 & 0.02 & -0.07 & -0.09 & 0.09 \\
\hline
\end{tabular}

Spearman correlation coefficient $(\rho)$ was used to identify associations between biomarkers and clinical factors. Only two factors were moderately associated: duration of bone metastases with BSP and TGF- $\beta$ (highlighted in bold above)

\section{Discussion}

Increasing interest in de-escalated bone-targeted therapies has been driven by concerns around the balance between intravenous bisphosphonate benefit and harm rather than trying to deliver the optimal frequency of drug based on individual patients' needs [3]. De-escalating bone-targeted therapy in low-risk patients has clear advantages for both the patients (less visits to the centre for treatment, and possibly less toxicity), and the health care system (both through direct and indirect costs) provided that de-escalation is not associated with a worsening of patient outcomes. Surveys have shown that the concept of de-escalation of therapy is acceptable to both oncologists [6] and patients with bone metastases [43].

There is significant heterogeneity in current de-escalation trials in terms of eligibility criteria, bisphosphonate used (mostly zoledronic acid) and duration of intravenous bisphosphonate therapy prior to study entry (ranging from bisphosphonate naïve [22], $\geq 3$ months [20], to 9-12 [18] months of prior monthly therapy). Interpretation of study findings is further confounded by the different outcomes measured. While some use SREs as the primary endpoint, others have used biomarkers of bone turnover such as NTx [22] and CTx [20] as surrogates of SRE risk. Thus, even with the publication of the ZOOM trial [18] the findings of a recent systematic review would suggest that clinical equipoise still exists [44]. Although biomarker-driven studies have advantages, they should only be used for planning larger definitive studies [6]. Our current data also questions their use as prognostic markers of SRE risk. In patients deemed 'low-risk', the most commonly used markers, namely CTx, NTx, BSAP and P1NP were not significantly different between patients who experienced versus those that did not experience on study SREs.
Of the 71 patients who entered the study, $61 \%$ completed 48 weeks of de-escalated therapy, $14.1 \%$ came off study early due to elevation of CTx $>600 \mathrm{ng} / \mathrm{L}$ and $12.7 \%$ due to on-study SRE. These results are within the $95 \% \mathrm{CI}$ of our previous study, where $72 \%$ of patients treated with 12 -weekly pamidronate maintained their telopeptides in the low risk range. This suggests that serum CTx $<600 \mathrm{ng} / \mathrm{L}$ after $\geq 3$ months of IV bisphosphonate therapy may identify a patient population at particularly low risk of subsequent SREs, and hence identify likely candidates for more routine use of de-escalated therapy [20].

Low baseline CTx levels were associated with completing study in univariate analysis, which is not surprising given that rises in CTx above $600 \mathrm{ng} / \mathrm{L}$ was a mandated reason to come off study. However, baseline CTx levels in this low-risk cohort did not correlate with the occurrence of an on study SRE. This is likely due to the small sample size in our present study.

The inability of CTx to prognosticate for SRE occurrence led us to evaluate other exploratory biomarkers at baseline to determine whether any of these could be useful for assisting in determining SRE risk in patients with CTx levels $<600 \mathrm{ng} / \mathrm{L}$. In addition to bone turnover markers frequently used in other studies (i.e. uNTx and P1NP), we also examined the levels of TGF- $\beta$, activin A and BSP. TGF- $\beta$ plays a critical role in osteolytic metastatic disease [45], and correlates with breast cancer stage and bone metastasis [31, 32]. Recent studies have also implicated activin A in metastatic and osteoclastic processes [33-35], and plasma levels of activin A are higher in breast cancer patients with bone metastases as compared to those without, and positively correlate with bone metastatic burden [36]. Tumour-derived expression of BSP is also correlated with development of osseous metastases [40]. Unfortunately, none of the standard 
Table 3 Prognostic factors of completion of therapy

\begin{tabular}{|c|c|c|c|}
\hline & $N$ & $\begin{array}{l}\text { Odds ratio } \\
(95 \% \mathrm{CI})\end{array}$ & $p$ value \\
\hline \multicolumn{4}{|l|}{ Univariate analyses } \\
\hline Weight & 71 & $1.00(0.96,1.04)$ & 0.93 \\
\hline Height & 71 & $0.96(0.89,1.04)$ & 0.30 \\
\hline BSA & 71 & $0.78(0.05,12.51)$ & 0.86 \\
\hline Duration of bone metastases & 70 & $1.00(0.98,1.03)$ & 0.84 \\
\hline PTH & 71 & $0.95(0.89,1.02)$ & 0.17 \\
\hline Vitamin D (/10 units) & 71 & $1.20(1.03,1.39)$ & 0.017 \\
\hline FACT-BP Subscale & 71 & $1.01(0.96,1.05)$ & 0.82 \\
\hline Baseline CTx (/10 units) & 71 & $0.96(0.93,0.99)$ & 0.007 \\
\hline BSAP & 70 & $0.88(0.77,1.01)$ & 0.066 \\
\hline NTx (/100 units) & 63 & $0.62(0.42,0.92)$ & 0.017 \\
\hline $\mathrm{P} 1 \mathrm{NP}$ (/1,000 units) & 63 & $0.99(0.97,1.01)$ & 0.41 \\
\hline BSP (/10 units) & 63 & $0.86(0.77,0.95)$ & 0.003 \\
\hline TGF- $\beta$ & 63 & $1.04(0.95,1.14)$ & 0.43 \\
\hline Activin A (/100 units) & 63 & $0.96(0.91,1.02)$ & 0.19 \\
\hline BPI-severity & 70 & $1.00(0.92,1.09)$ & 0.93 \\
\hline BPI-interference & 69 & $1.02(0.97,1.06)$ & 0.44 \\
\hline $\begin{array}{l}\text { Metastatic disease (bone } \\
\text { only vs bone plus other) }\end{array}$ & 65 & $1.51(0.56,4.06)$ & 0.41 \\
\hline \multicolumn{4}{|l|}{ Multivariate analyses } \\
\hline BSP (/10 units) & 63 & $0.82(0.72,0.93)$ & 0.003 \\
\hline NTx (/100 units) & 63 & $0.62(0.39,0.97)$ & 0.035 \\
\hline Vitamin D (/10 units) & 63 & $1.27(1.04,1.54)$ & 0.017 \\
\hline
\end{tabular}

In univariate analyses, vitamin D, CTx, NTx and BSP were all statistically significant for completion of therapy. In the multivariate analyses, BSP, NTx and Vitamin D all remained statistically significant prognostic factors of completion of therapy

(CTx, BSAP, NTx or P1NP) nor additional experimental biomarkers (TGF- $\beta$, activin A or BSP) showed any significant association with SRE incidence in these low-risk patients at baseline. However, among the experimental biomarkers, it should be noted that baseline levels of BSP were moderately associated with duration of bone metastases, and were also associated with failure to complete the study despite the fact that BSP did not reach statistical significance for an association with incidence of on-study SRE. Of all the baseline parameters measured, only baseline pain scores as measured by BPIseverity was prognostic for increased risk of SRE. This finding highlights the utility in using pain score assessment tools in these types of studies.

Our study has several limitations, including: use of a biomarker surrogate for defining a population at low risk of SREs, a relatively small sample size, the variable duration of prior 3-4 weekly IV bisphosphonate use and the use of pamidronate rather than more potent bisphosphonates such as zoledronic acid. Given our current findings regarding the
Table 4 Prognostic factors of on-study SRE

\begin{tabular}{|c|c|c|c|}
\hline & $N$ & $\begin{array}{l}\text { Odds ratio } \\
(95 \% \mathrm{CI})\end{array}$ & $p$ value \\
\hline \multicolumn{4}{|l|}{ Univariate analyses } \\
\hline Weight & 71 & $1.01(0.97,1.06)$ & 0.60 \\
\hline Height & 71 & $1.00(0.89,1.12)$ & 0.95 \\
\hline BSA & 71 & $2.57(0.05,143.61)$ & 0.65 \\
\hline Duration of bone metastases & 70 & $1.02(0.99,1.04)$ & 0.24 \\
\hline PTH & 71 & $1.05(0.99,1.12)$ & 0.12 \\
\hline Vitamin D (/10 units) & 71 & $0.97(0.80,1.17)$ & 0.75 \\
\hline FACT-BP Subscale & 71 & $0.99(0.93,1.05)$ & 0.66 \\
\hline Baseline CTx (/10 units) & 71 & $1.01(0.97,1.04)$ & 0.70 \\
\hline BSAP & 70 & $0.99(0.88,1.12)$ & 0.85 \\
\hline NTx (/100 units) & 63 & $0.98(0.77,1.25)$ & 0.86 \\
\hline P1NP (/1,000 units) & 63 & $1.02(0.99,1.04)$ & 0.27 \\
\hline BSP (/10 units) & 63 & $1.07(0.97,1.19)$ & 0.19 \\
\hline TGF- $\beta$ & 63 & $0.88(0.76,1.03)$ & 0.11 \\
\hline Activin A (/100 units) & 63 & $0.98(0.89,1.08)$ & 0.73 \\
\hline BPI-severity & 70 & $1.15(1.03,1.28)$ & 0.017 \\
\hline BPI-interference & 69 & $1.04(0.99,1.10)$ & 0.11 \\
\hline $\begin{array}{l}\text { Metastatic disease (bone only } \\
\text { vs bone plus other) }\end{array}$ & 65 & $0.40(0.09,1.78)$ & 0.23 \\
\hline Prior SRE (ordinal) & 71 & $1.18(0.52,2.70)$ & 0.70 \\
\hline Prior SRE ( $\geq 1$ vs none) & 71 & $1.71(0.38,7.75)$ & 0.48 \\
\hline \multicolumn{4}{|l|}{ Multivariate analyses } \\
\hline BPI-Severity & 70 & $1.15(1.03,1.28)$ & 0.017 \\
\hline
\end{tabular}

Results for the prognostic ability of various factors for a patient having at least one SRE. BPI-severity score was the only factor statistically significant in the univariate or multivariate analyses

lack of association between CTx and SRE incidence in this low risk cohort, other biomarkers including pain measurement should be considered in these low risk cohorts in future studies addressing use of de-escalated regimens of bone-targeting agents. Other potential indicators of bisphosphonate efficacy such as control of circulating tumour cells or levels of $\gamma \delta$ T-cells should also be further investigated as the recent literature suggests a potential role in efficacy of bisphosphonates [46-49]. Our trial and experimental biomarker findings are also limited by the fact that a small number of clinical events have occurred within the 48-week follow-up of the study. These findings also have important implications for the design of future studies addressing these issues in low risk populations, and suggest that to determine treatment effects on SRE risk, longer durations of follow-up are required to perform statistically powered analysis with sufficient numbers of events. However, it remains possible that changes in biomarker levels over time may provide better assessment of parameters such as SRE risk. 
In conclusion, reducing the frequency of IV bisphosphonate administration could be of benefit to both patients and the health care system provided it is not associated with worse patient outcomes. In the current study we have shown that the majority of patients with a baseline serum CTx level $<600 \mathrm{ng} / \mathrm{L}$ after at least 3 months of IV pamidronate have a low risk of SREs with 1 year of de-escalated therapy. However, no association between CTx levels and on-study SREs was observed in this low risk cohort, highlighting the need for identification of markers that are prognostic for SREs. Of all the measured baseline parameters, only pain as measured by BPI severity scores was associated with on-study SREs, hence our data suggest that pain measures may be a promising candidate marker of SRE risk in these low-risk patients. The results of our present study along with our previous pilot randomised study [20] and ZOOM [18] suggest that de-escalated 12 weekly bisphosphonate treatment will likely become increasingly used after a limited period of 3-4 weekly treatment. However, there is a need for completion and analysis of larger more definitive trials, including those with denosumab, to ensure the safety of this strategy.

Acknowledgments We would like to acknowledge Dianne Robbins, Patti Spencer, Joanne Roach and Ranjeeta Mallick in trial coordination and initial statistical planning as well as the members of the Data Safety Monitoring Committee. Preliminary data were presented in part at the 2012 San Antonio Breast Cancer Symposium. Bouganim N et al., Cancer Research 2012; 72;24 [P3-13-05] and Addison et al., Cancer Research: 2012; 72,24 [P2-05-13]. The trial was registered at Ontario Cancer Trials (OCT 1213) and www.cana diancancertrials.ca (10-047). This study was funded by the Canadian Breast Cancer Foundation-Ontario Chapter, and in part with the support of the Ontario Institute for Cancer Research through funding provided by the Government of Ontario.

Conflict of interest Financial disclosures apply for: research funding: Novartis (MC), attendance at advisory boards: Amgen (MC, EA, SH, SD), Novartis (MC, SH) and honoraria for talks: Amgen (MC) and Novartis (MC, SD). All other authors have no conflicts of interest to declare.

Open Access This article is distributed under the terms of the Creative Commons Attribution Noncommercial License which permits any noncommercial use, distribution, and reproduction in any medium, provided the original author(s) and the source are credited.

\section{References}

1. Purohit OP, Radstone CR, Anthony C, Kanis JA, Coleman RE (1995) A randomised double-blind comparison of intravenous pamidronate and clodronate in the hypercalcaemia of malignancy. Br J Cancer 72(5):1289-1293

2. Kimmel DB (2007) Mechanism of action, pharmacokinetic and pharmacodynamic profile, and clinical applications of nitrogencontaining bisphosphonates. J Dent Res 86(11):1022-1033
3. Kuchuk I, Clemons M, Addison C (2012) Time to put an end to the "one size fits all" approach to bisphosphonate use in patients with metastatic breast cancer? Curr Oncol 19(5):e303-e304. doi: $10.3747 /$ co.19.1009

4. Verma S, Kerr-Cresswell D, Dranitsaris G, Charbonneau F, Trudeau M, Yogendran G, Cesta AM, Clemons M (2004) Bisphosphonate use for the management of breast cancer patients with bone metastases: a survey of Canadian Medical Oncologists. Support Care Cancer 12(12):852-858. doi:10.1007/s00520-0040671-9

5. Clemons M, Enright K, Cesta A, Charbonneau F, Chow E, Warr D, Kee-Cresswell D, Chang J, Yogendran G, Trudeau M, De Angelis C, Cottrell W, Dranitsaris G (2004) Do physicians follow systemic treatment and funding policy guidelines? Can J Clin Pharmacol 11(1):e168-e178

6. Hutton B, Addison C, Mazzarello S, Joy A, Bouganim N, Fergusson D, Clemons M (2013) De-escalated administration of bone-targeted agents in patients with breast and prostate cancer: a survey of Canadian Oncologists. J Bone Oncol 2(2):77-83

7. Holen I, Coleman RE (2010) Bisphosphonates as treatment of bone metastases. Curr Pharm Des 16(11):1262-1271

8. Hortobagyi GN (2005) Moving into the future: treatment of bone metastases and beyond. Cancer Treat Rev 31(Suppl 3):9-18. doi:10.1016/j.ctrv.2005.09.003

9. Bouganim N, Clemons MJ (2011) Bone-targeted agents in the treatment of bone metastases: RANK outsider or new kid on the block? Future Oncol 7(3):381-383. doi:10.2217/fon.10.192

10. Rosen LS, Gordon D, Kaminski M, Howell A, Belch A, Mackey J, Apffelstaedt J, Hussein MA, Coleman RE, Reitsma DJ, Chen BL, Seaman JJ (2003) Long-term efficacy and safety of zoledronic acid compared with pamidronate disodium in the treatment of skeletal complications in patients with advanced multiple myeloma or breast carcinoma: a randomized, double-blind, multicenter, comparative trial. Cancer 98(8):1735-1744. doi:10. 1002/cncr.11701

11. Aapro M, Saad F, Costa L (2010) Optimizing clinical benefits of bisphosphonates in cancer patients with bone metastases. Oncologist 15(11):1147-1158. doi:10.1634/theoncologist.20070245

12. Giordano SH, Fang S, Duan Z, Kuo YF, Hortobagyi GN, Goodwin JS (2008) Use of intravenous bisphosphonates in older women with breast cancer. Oncologist 13(5):494-502. doi:10. 1634/theoncologist.2007-0200

13. Launay-Vacher V, Gligorov J, Le Tourneau C, Janus N, Spano JP, Ray-Coquard I, Oudard S, Pourrat X, Morere JF, Deray G, Beuzeboc P, Renal I, Anticancer Medications Study G (2010) Prevalence of renal insufficiency in breast cancer patients and related pharmacological issues. Breast Cancer Res Treat 124(3):745-753. doi:10.1007/s10549-008-0131-1

14. Arslan C, Aksoy S, Dizdar O, Dede DS, Harputluoglu H, Altundag K (2011) Zoledronic acid and atrial fibrillation in cancer patients. Support Care Cancer 19(3):425-430. doi:10.1007/ s00520-010-0868-Z

15. John Camm A (2010) Review of the cardiovascular safety of zoledronic acid and other bisphosphonates for the treatment of osteoporosis. Clin Ther 32(3):426-436. doi:10.1016/j.clinthera. 2010.03.014

16. Wilkinson GS, Baillargeon J, Kuo YF, Freeman JL, Goodwin JS (2010) Atrial fibrillation and stroke associated with intravenous bisphosphonate therapy in older patients with cancer. J Clin Oncol 28(33):4898-4905. doi:10.1200/JCO.2010.28.7524

17. Mariotti A (2008) Bisphosphonates and osteonecrosis of the jaws. J Dent Educ 72(8):919-929

18. Amadori D, Aglietta M, Alessi B, Gianni L, Ibrahim T, Farina G, Gaion F, Bertoldo F, Santini D, Rondena R, Bogani P, Ripamonti C (2012) ZOOM: A prospective, randomized trial of zoledronic 
acid (ZOL; q 4 wk vs q $12 \mathrm{wk}$ ) for long-term treatment in patients with bone-metastatic breast cancer (BC) after $1 \mathrm{yr}$ of standard ZOL treatment. J Clin Oncol 30 (suppl; abstr 9005)

19. Amadori D, Aglietta M, Alessi B, Gianni L, Ibrahim T, Farina G, Gaion F, Bertoldo F, Santini D, Rondena R, Bogani P, Ripamonti C (2013) Efficacy and safety of 12-weekly versus 4-weekly zoledronic acid for prolonged treatment of patients with bone metastases from breast cancer (ZOOM): a phase 3, open-label, randomised, non-inferiority trial. Lancet Oncol 14(7):663-670

20. Amir E, Freedman O, Carlsson L, Dranitsaris G, Tomlinson G, Laupacis A, Tannock IF, Clemons M (2012) Randomized feasibility study of de-escalated (Every $12 \mathrm{wk}$ ) versus standard (Every 3 to $4 \mathrm{wk}$ ) intravenous pamidronate in women with low-risk bone metastases from breast cancer. Am J Clin Oncol. doi:10.1097/ COC.0b013e3182568f7a

21. Bouganim N, Vandermeer L, Kuchuk I, Dent S, Hopkins S, Song X, Robbins D, Spencer P, Mazzarello S, Hilton J, Amir E, Dranitsaris G, Addison C, Mallick R, Clemons M (2012) Evaluating efficacy of de-escalated bisphosphonate therapy in metastatic breast cancer patients at low-risk of skeletal related events. TRIUMPH: A pragmatic multicentre trial. J Cancer Res 72 (24)

22. Coleman RE, Wright J, Houston S, Agrawal R, Purohit OP-K, Hayward L, Simmonds P, Waterhouse A, Marshall H, Investigators B (2012) Randomized trial of marker-directed versus standard schedule zoledronic acid for bone metastases from breast cancer. J Clin Oncol 30(15):511

23. NCT00424983 (2006) A prospective, randomized, double-blind, stratified, multi-center, 2-arm trial of the continued efficacy and safety of zoledronic acid (every 4 weeks vs. every 12 weeks) in patients with documented bone metastases from Breast cancer. http://clinicaltrials.gov/ct2/show/record/NCT00320710. Accessed 23 Jan 2014

24. NCT00424983 (2009) A stratified, randomized, open-label, multicenter comparative 2-arm trial of PK, PD, and safety of zoledronic acid infusions administered monthly vs. every 3 -month, in multiple myeloma patients with malignant bone lesions, and breast cancer patients with bone metastasis, who have received $9-12 *$ doses of zoledronic acid over the prior year. http://clinicaltrials.gov/ct2/ show/NCT00424983. Accessed 23 Jan 2014

25. NCT00869206 (2009) A randomized, phase III study of standard dosing versus longer dosing interval of zoledronic acid in metastatic cancer. http://www.clinicaltrials.gov/ct2/show/NCT00869206. Accessed 23 Jan 2014

26. Lipton A, Costa L, Coleman RE (2011) Bone turnover markers: tools for prognosis and monitoring response to bisphosphonates? Breast Dis 33(2):59-69. doi:10.3233/BD-2010-0327

27. Clemons M, Dranitsaris G, Ooi W, Cole DE (2008) A phase II trial evaluating the palliative benefit of second-line oral ibandronate in breast cancer patients with either a skeletal related event (SRE) or progressive bone metastases (BM) despite standard bisphosphonate (BP) therapy. Breast Cancer Res Treat 108(1):79-85

28. Clemons MJ, Dranitsaris G, Ooi WS, Yogendran G, Sukovic T, Wong BY, Verma S, Pritchard KI, Trudeau M, Cole DE (2006) Phase II trial evaluating the palliative benefit of second-line zoledronic acid in breast cancer patients with either a skeletalrelated event or progressive bone metastases despite first-line bisphosphonate therapy. J Clin Oncol 24(30):4895-4900. doi:10. 1200/JCO.2006.05.9212

29. Harris K, Li K, Flynn C, Chow E (2007) Worst, average or current pain in the Brief Pain Inventory: which should be used to calculate the response to palliative radiotherapy in patients with bone metastases? Clin Oncol (R Coll Radiol) 19(7):523-527. doi:10.1016/j.clon.2007.04.007

30. Broom R, Du H, Clemons M, Eton D, Dranitsaris G, Simmons C, Ooi W, Cella D (2009) Switching breast cancer patients with progressive bone metastases to third-generation bisphosphonates: measuring impact using the Functional Assessment of Cancer Therapy-Bone Pain. J Pain Symptom Manag 38(2):244-257

31. Baselga J, Rothenberg ML, Tabernero J, Seoane J, Daly T, Cleverly A, Berry B, Rhoades SK, Ray CA, Fill J, Farrington DL, Wallace LA, Yingling JM, Lahn M, Arteaga C, Carducci M (2008) TGF-beta signalling-related markers in cancer patients with bone metastasis. Biomarkers 13(2):217-236. doi:10.1080/ 13547500701676019

32. Desruisseau S, Palmari J, Giusti C, Romain S, Martin PM, Berthois Y (2006) Determination of TGFbetal protein level in human primary breast cancers and its relationship with survival. Br J Cancer 94(2):239-246. doi:10.1038/sj.bjc.6602920

33. Leto G, Incorvaia L, Badalamenti G, Tumminello FM, Gebbia N, Flandina C, Crescimanno M, Rini G (2006) Activin A circulating levels in patients with bone metastasis from breast or prostate cancer. Clin Exp Metastasis 23(2):117-122. doi:10.1007/s10585006-9010-5

34. Risbridger GP, Schmitt JF, Robertson DM (2001) Activins and inhibins in endocrine and other tumors. Endocr Rev 22(6):836-858

35. Fuller K, Bayley KE, Chambers TJ (2000) Activin A is an essential cofactor for osteoclast induction. Biochem Biophys Res Commun 268(1):2-7. doi:10.1006/bbrc.2000.2075

36. Reis FM, Cobellis L, Tameirao LC, Anania G, Luisi S, Silva IS, Gioffre W, Di Blasio AM, Petraglia F (2002) Serum and tissue expression of activin a in postmenopausal women with breast cancer. J Clin Endocrinol Metab 87(5):2277-2282

37. Dean-Colomb W, Hess KR, Young E, Gornet TG, Handy BC, Moulder SL, Ibrahim N, Pusztai L, Booser D, Valero V, Hortobagyi GN, Esteva FJ (2013) Elevated serum P1NP predicts development of bone metastasis and survival in early-stage breast cancer. Breast Cancer Res Treat 137(2):631-636. doi:10.1007/ s10549-012-2374-0

38. Pollmann D, Siepmann S, Geppert R, Wernecke KD, Possinger K, Luftner D (2007) The amino-terminal propeptide (PINP) of type I collagen is a clinically valid indicator of bone turnover and extent of metastatic spread in osseous metastatic breast cancer. Anticancer Res 27(4A): 1853-1862

39. Luftner D, Jozereau D, Schildhauer S, Geppert R, Muller C, Fiolka G, Wernecke KD, Possinger K (2005) PINP as serum marker of metastatic spread to the bone in breast cancer patients. Anticancer Res 25(3A): 1491-1499

40. Diel IJ, Solomayer EF, Seibel MJ, Pfeilschifter J, Maisenbacher H, Gollan C, Pecherstorfer M, Conradi R, Kehr G, Boehm E, Armbruster FP, Bastert G (1999) Serum bone sialoprotein in patients with primary breast cancer is a prognostic marker for subsequent bone metastasis. Clin Cancer Res 5(12):3914-3919

41. Leeming DJ, Koizumi M, Byrjalsen I, Li B, Qvist P, Tanko LB (2006) The relative use of eight collagenous and noncollagenous markers for diagnosis of skeletal metastases in breast, prostate, or lung cancer patients. Cancer Epidemiol Biomarkers Prev 15(1):32-38. doi:10.1158/1055-9965.EPI-05-0492

42. Coleman RE, Major P, Lipton A, Brown JE, Lee KA, Smith M, Saad F, Zheng M, Hei YJ, Seaman J, Cook R (2005) Predictive value of bone resorption and formation markers in cancer patients with bone metastases receiving the bisphosphonate zoledronic acid. J Clin Oncol 23(22):4925-4935. doi:10.1200/JCO.2005.06.091

43. Hutton B, Morretto P, Emmenegger U, Mazarello S, Kuchuk I, Addison C, Crawley F, Canil C, Malone S, Berry S, Fergusson D, Clemons M (2013) Bone-targeted agent use for bone metastases from breast cancer and prostate cancer: a patient survey. J Bone Oncol (in press)

44. Hutton B, Addison C, Campbell K, Fergusson D, Mazarello S, Clemons M (2013) A systematic review of de-escalated versus 3-4 weekly treatment with bone targeted agents for patients with bone metastases from breast cancer. J Bone Oncol 
45. Ivanovic V, Todorovic-Rakovic N, Demajo M, Neskovic-Konstantinovic Z, Subota V, Ivanisevic-Milovanovic O, NikolicVukosavljevic D (2003) Elevated plasma levels of transforming growth factor-beta 1 (TGF-beta 1) in patients with advanced breast cancer: association with disease progression. Eur J Cancer 39(4):454-461

46. Santini D, Martini F, Fratto ME, Galluzzo S, Vincenzi B, Agrati C, Turchi F, Piacentini P, Rocci L, Manavalan JS, Tonini G, Poccia F (2009) In vivo effects of zoledronic acid on peripheral gammadelta $\mathrm{T}$ lymphocytes in early breast cancer patients. Cancer Immunol Immunother 58(1):31-38. doi:10.1007/s00262008-0521-6

47. Meraviglia S, Eberl M, Vermijlen D, Todaro M, Buccheri S, Cicero G, La Mendola C, Guggino G, D'Asaro M, Orlando V, Scarpa F, Roberts A, Caccamo N, Stassi G, Dieli F, Hayday AC (2010) In vivo manipulation of Vgamma9Vdelta2 $\mathrm{T}$ cells with zoledronate and low-dose interleukin-2 for immunotherapy of advanced breast cancer patients. Clin Exp Immunol 161(2):290-297. doi:10.1111/j.1365-2249.2010.04167.x

48. Aft R, Naughton M, Trinkaus K, Watson M, Ylagan L, ChavezMacGregor M, Zhai J, Kuo S, Shannon W, Diemer K, Herrmann V, Dietz J, Ali A, Ellis M, Weiss P, Eberlein T, Ma C, Fracasso PM, Zoberi I, Taylor M, Gillanders W, Pluard T, Mortimer J, Weilbaecher K (2010) Effect of zoledronic acid on disseminated tumour cells in women with locally advanced breast cancer: an open label, randomised, phase 2 trial. Lancet Oncol 11(5):421-428. doi:10. 1016/S1470-2045(10)70054-1

49. Banys M, Solomayer EF, Gebauer G, Janni W, Krawczyk N, Lueck HJ, Becker S, Huober J, Kraemer B, Wackwitz B, Hirnle P, Wallwiener D, Fehm T (2013) Influence of zoledronic acid on disseminated tumor cells in bone marrow and survival: results of a prospective clinical trial. BMC Cancer 13:480. doi:10.1186/ 1471-2407-13-480 